ISAHP 1999, Kobe, Japan, August 12-14, 1999

\title{
An Application of Descriptive Analytic Hierarchy Process to Siting a Refuse Incineration Plant
}

\author{
Shinichi Fujita and Hiroyuki Tamura \\ Bureau of Public Enterprise, Osaka Prefectural Government, \\ 2-Chome, Ootemae, Chuo-Ku, Osaka 540-8570, Japan \\ TEL +81-6-6941-1532 FAX +81-6-6944-6990 \\ Graduate School of Engineering Science, Osaka University, \\ 1-3 Machikaneyama, Toyonaka, Osaka 560-8531, Japan \\ kigyokanri@office.pref.osaka.jp/tamura@sys.es.osaka-u.ac.jp
}

\begin{abstract}
In this paper, a municipal decision support methodology is proposed to evaluate the location of refuse incineration plant using the model of descriptive extension of Analytic Hierarchy Process, called D-AHP. In this model, the rank reversal phenomena are legitimately observed and explanatory. The alternative sites of the refuse incineration. plant which disposes the municipal waste are located in a hypothetical city, and the alternatives are evaluated. The results of the evaluation show that D-AHP is useful for the case that the number of alternatives is changeable, such as the siting of the refuse incineration plant.
\end{abstract}

\section{Introduction}

The total amount of municipal waste which generally consists of the domestic waste and the paper and kitchen garbage from office was about 50 million-ton/year in 1994 in Japan, and $75.5 \%$ of them were incinerated (Ministry of Health and Welfare, 1998). The responsibility to dispose municipal waste is lies with the mayor of this municipal. Therefore, the refuse incineration plant has to be constructed and operated by the municipal government itself or the organization consisted of several municipal governments.

Though the efforts to reduce the amount of wastes have been done by municipal government, citizen and officers, the amount of municipal waste is increasing year by year. It becomes one of the very important job to the municipal government to construct the refuse incineration plant. Though it is very difficult to get the consensus of the residents near the area intend to construct the refuse incineration plant, because they fear and hate to the various environmental impacts due to the construction and operation of the plant, especially dioxin emitted from the plant.

In this paper, a decision support methodology to evaluate the location of refuse incineration plant is proposed to support the municipal decision making. There are many items to evaluate the location of refuse incineration plant, and the relation between items is very complicated, then the Analytical Hierarchy Process is used to evaluate the alternatives (Saaty, 1980).

Thought, It is known that AHP has a shortcoming called rank reversal phenomena. When a new alternative is added to an existing set of alternatives or when an alternative is removed from an existing set of alternatives, the rank of the remaining alternatives may be changed (Belton and Gear, 1983; Barzillai et al., 1987; Dyer, 1990). In the decision of the location of refuse incineration plant, there are many cases the number of alternatives may change. For example, the lot of the most desirable location could not be gotten and a top ranked alternative might be removed, or the area regulated by the law might become the new proposed site if the regulation became relaxed. Therefore, the 
Descriptive Analytic Hierarchy Process (D-AHP) is used, in this model the rank reversal phenomena are legitimately observed and explanatory (Tamura et al., 1997).

\section{Algorithm of D-AHP}

The D-AHP contains two characteristics; preference characteristics and status characteristics (Tamura et al., 1997). The preference characteristics represent the degree of satisfaction of each alternative with respect to each criterion, and the status characteristics $C$ represent the evaluated value of a set of alternatives, and $C$ is calculated by following equation.

$$
C=\left|\log _{\rho}\left(\prod_{i=1}^{\mathrm{n}} w_{i}\right)^{1 / \mathrm{n}}\right|
$$

Where, $w_{i}$ is the weighting coefficient for each criterion, and $\rho$ is a constant usually $\rho=9$.

The evaluation of each alternative for multiple criteria is performed by integrating these two characteristics. The algorithm of D-AHP is as follows.

Step 1. Multiple criteria and multiple alternatives are arranged in a hierarchical structure.

Step 2. Compare the criteria pairwise which is arranged in the one level higher level of alternatives. Eigenvector corresponding to the maximum eigenvalue of the pairwise comparison matrix is normalized to sum to 1 . The priority obtained is set to be preference characteristics which represent basic priority.

Step 3. For each criterion, aspiration level is asked to DM. A hypothetical alternative which gives aspiration level for all the criteria is added to a set of alternatives. Including this hypothetical alternative pairwise comparison matrix for each criterion is evaluated. Eigenvector corresponding to the maximum eigenvalue is normalized so that the entry for this hypothetical alternative is equal to 1 .

Step 4. If consistency index (C.I.) $=0$ for each comparison matrix, preference characteristics, that is, basic priority is used as the weighting coefficient for each criterion. If C.I. $\neq 0$ for some criteria the priority for these criteria is revised by using following equation.

where

$$
\begin{aligned}
& w_{i}=w_{i}^{B} \times C^{f(C . I .)} \\
& 0 \leqq C \leqq 1 \\
& 0 \leqq f(C . I .) \leqq 1 \text {, }
\end{aligned}
$$

$$
f(C . I .)=0, \text { for } C . I=0
$$

Where, $w_{i}^{B}$ is basic weight obtained from preference characteristics, and $C$ is the status characteristics that denotes the average importance of alternatives, and $f(C . I$.$) is called reliability function.$

Step 5. If some priorities are revised taking into account the status characteristics, the priority for each criterion is normalized to sum to 1 .

Step 6. Overall weight is evaluated. If there exists upper level in the hierarchy, go to Step 7. Otherwise, stop.

Step 7. Evaluate pairwise comparison matrix of criteria with respect to each criterion in the higher level. If some pairwise comparison matrices are not consistent, evaluate status characteristics and revise 
the priority. Go to Step 6 .

\section{Modeling of Location Evaluation of the Plants}

The alternative sites of the refuse incineration plant were set in a modeling city, those were at the hilly area, plain area and middle area in a city (see Fig. 1). The conditions of the incineration plant is shown in table 1.

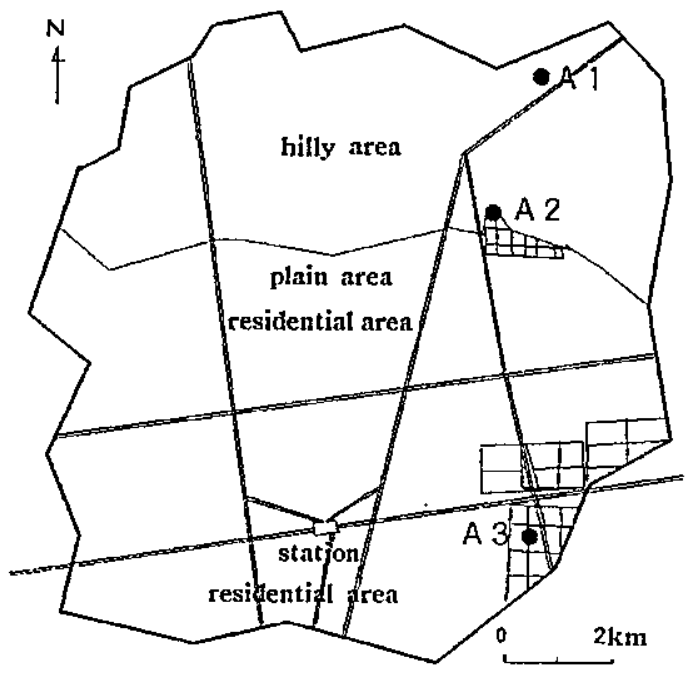

Fig. 1 The alternative sites in a modeling city
Table 1 The conditions of the refuse incineration plant

\begin{tabular}{|l|l|}
\hline the area of the plant & $2 \mathrm{ha}$ \\
\hline incineration ability & $300 \mathrm{ton} /$ day \\
\hline height of the chimney & $60 \mathrm{~m}$ \\
\hline exhaust gas temperature & $100^{\circ} \mathrm{C}$ \\
\hline gas emission volume(dry) & $56,000 \mathrm{Nm}^{3} / \mathrm{hour}^{\circ}$ \\
\hline dioxin compound & $0.1 \mathrm{ng}-\mathrm{TEQ} / \mathrm{Nm}^{3}$ \\
\hline sulfur oxides & $50 \mathrm{ppm}$ \\
\hline nitrogen oxides & $50 \mathrm{ppm}$ \\
\hline dust & $0.02 \mathrm{~g} / \mathrm{Nm}^{3}$ \\
\hline
\end{tabular}

The items to evaluate the location of refuse incineration plant is shown in table 2 , those were derived by asking to the municipal officers attending to the waste disposal planning.

Table 2 The items to evaluate the location of the refuse incineration plant

\begin{tabular}{|c|c|c|}
\hline \multirow[t]{4}{*}{$\begin{array}{l}\text { Convenience to } \\
\text { construct the plant }\end{array}$} & cost & $\begin{array}{l}\text { cost to buy the lot } \\
\text { cost to reclaim the land } \\
\text { cost to construct the facilities }\end{array}$ \\
\hline & $\begin{array}{l}\text { impact to the natural } \\
\text { environment }\end{array}$ & $\begin{array}{l}\text { impact to the plants } \\
\text { impact to the animals }\end{array}$ \\
\hline & impact to the culture asset & the possibility of the reserved culture asset \\
\hline & regulation of land use & $\begin{array}{l}\text { regulation of to reclaim the land } \\
\text { protection forest area } \\
\text { etc. }\end{array}$ \\
\hline \multirow{3}{*}{$\begin{array}{l}\text { Convenience to } \\
\text { operate the plant }\end{array}$} & commute of the worker & distance from the nearest railway station \\
\hline & garbage transportation & average distance from the residence \\
\hline & water resource & $\begin{array}{l}\text { water supply } \\
\text { sewage }\end{array}$ \\
\hline \multirow[t]{3}{*}{$\begin{array}{l}\text { Resident's } \\
\text { consensus }\end{array}$} & $\begin{array}{l}\text { environmental impact } \\
\text { due to the facility }\end{array}$ & $\begin{array}{l}\text { air pollution } \\
\text { offensive odor } \\
\text { noise }\end{array}$ \\
\hline & $\begin{array}{l}\text { environmental impact } \\
\text { due to the garbage truck }\end{array}$ & $\begin{array}{l}\text { air pollution to the resident near roads } \\
\text { noise to the resident near roads } \\
\text { offensive odor to the resident near roads }\end{array}$ \\
\hline & $\begin{array}{l}\text { impact of } \\
\text { existence of the plant }\end{array}$ & $\begin{array}{l}\text { obstruction of landscape } \\
\text { jamming }\end{array}$ \\
\hline
\end{tabular}


Then, the items indifferent among the alternatives are excluded, and to simplify the model, the following measures are done.

(i) Impact to the natural environment due to the construction of the plant is represented the area of deforestation.

(ii) Air pollution due to the operation of the plant is represented the maximum concentration of the dioxin at the residential area which exhausted from the chimney.

(iii) Environmental impact due to the garbage truck is represented the average length of the road in the residential area where the truck go through.

The concentration of dioxin at the residential area is shown in Fig. 2, which was calculated using plume model (Gifford, 1961) and puff

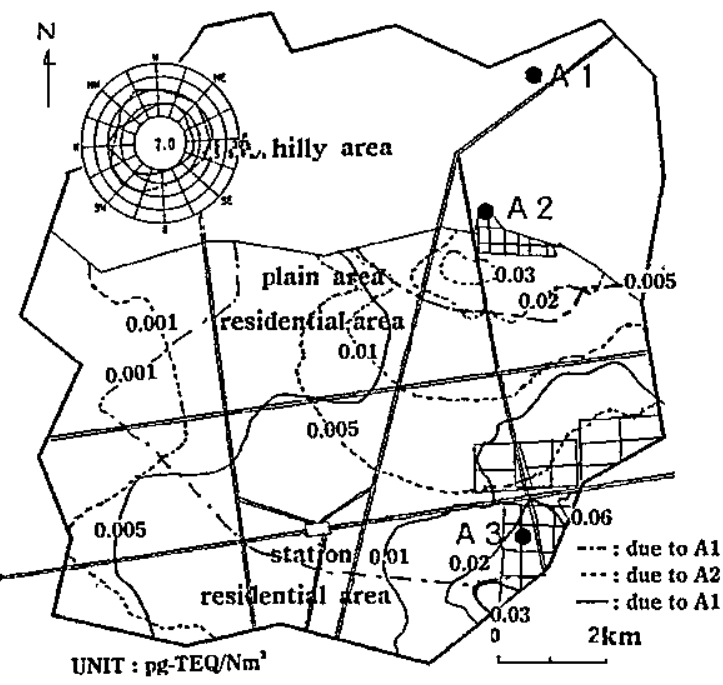

Fig. 2 The concentration of dioxin from the plant model (Turner, 1964), where TEQ means the Toxicity Equivalency Quality convert to the toxicity quality of $2,3,7,8$ tetrachlorodibenzodioxin.

In table 3, we show the items and their values of three alternatives (A1, A2, A3).

Table 3 The values of the items to evaluate the location of the refuse incineration plant

\begin{tabular}{|c|c|c|c|}
\hline \multirow[t]{4}{*}{$\begin{array}{l}\text { Convenience } \\
\text { to construct } \\
\text { the plant }\end{array}$} & \multirow[t]{2}{*}{$\cos t$} & cost to buy the lot & $\begin{array}{l}\text { A1: } 3,000 \mathrm{Yen} / \mathrm{m}^{2} \\
\text { A2: } 10,000 \mathrm{Yen} / \mathrm{m}^{2} \\
\text { A3: } 1 \text { millionYen } / \mathrm{m}^{2}\end{array}$ \\
\hline & & cost to reclaim the land & $\begin{array}{l}\text { AI: } 40,000 \mathrm{Yen} / \mathrm{m}^{2} \\
\text { A2: } 10,000 \mathrm{Yen} / \mathrm{m}^{2} \\
\text { A3: } 2,000 \mathrm{Yen} / \mathrm{m}^{2}\end{array}$ \\
\hline & $\begin{array}{l}\text { impact to the natural } \\
\text { environment }\end{array}$ & the area of deforestation & $\begin{array}{l}\text { A1: 2ha, A2: 1.2ha, } \\
\text { A3:0ha }\end{array}$ \\
\hline & $\begin{array}{l}\text { impact to } \\
\text { the culture asset }\end{array}$ & the possibility of the reserved culture asset & $\begin{array}{l}\text { A1: } 5 \%, \text { A2: } 15 \% \\
\text { A3: } 80 \%\end{array}$ \\
\hline \multirow{2}{*}{$\begin{array}{l}\text { Convenience } \\
\text { to operate } \\
\text { the plant }\end{array}$} & commute of the worker & distance from the nearest railway station & $\begin{array}{l}\text { Al: } 15 \mathrm{~km}, \mathrm{~A} 2: 10 \mathrm{~km}, \\
\text { A3: } 4 \mathrm{~km}\end{array}$ \\
\hline & garbage transportation & average distance from the residence & $\begin{array}{l}\mathrm{A} 1: 20 \mathrm{~km}, \mathrm{~A} 2: 15 \mathrm{~km}, \\
\mathrm{~A} 3: 8 \mathrm{~km} .\end{array}$ \\
\hline \multirow{6}{*}{$\begin{array}{l}\text { Resident's } \\
\text { consensus }\end{array}$} & \multirow{3}{*}{$\begin{array}{l}\text { environmental impact } \\
\text { due to the facility }\end{array}$} & air pollution & see figure 2 \\
\hline & & offensive odor & $\begin{array}{l}\text { A1: odor strength } 0 \\
\text { A2: odor strength } 1 \\
\text { A3: odor strength } 2\end{array}$ \\
\hline & & noise & $\begin{array}{l}\text { A1: smaller than } \\
\text { 30dB(A), A2: } 40 \mathrm{~dB}(\mathrm{~A}) \text {, } \\
\mathrm{A} 3: 50 \mathrm{~dB}(\mathrm{~A})\end{array}$ \\
\hline & $\begin{array}{l}\text { environmental impact } \\
\text { due to the garbage truck }\end{array}$ & $\begin{array}{l}\text { average length of the road in the resident } \\
\text { area where the garbage truck go through }\end{array}$ & $\begin{array}{l}\mathrm{A} 1: 10 \mathrm{~km}, \mathrm{~A} 2: 10 \mathrm{~km}, \\
\mathrm{~A} 3: 8 \mathrm{~km}\end{array}$ \\
\hline & \multirow[t]{2}{*}{$\begin{array}{l}\text { impact of } \\
\text { existence of the plant }\end{array}$} & obstruction of landscape & $\begin{array}{l}\text { A1: can not see, } \\
\text { A2: see a part of chimney, } \\
\text { A3: can see the facility }\end{array}$ \\
\hline & & jamming & $\begin{array}{l}\text { A1: no influence, } \\
\text { A2: almost no influence, } \\
\text { A3: need measures over } \\
100 \text { residents }\end{array}$ \\
\hline
\end{tabular}


We show the hierarchy structure to evaluate the location of refuse incineration plant, in Fig. 3.

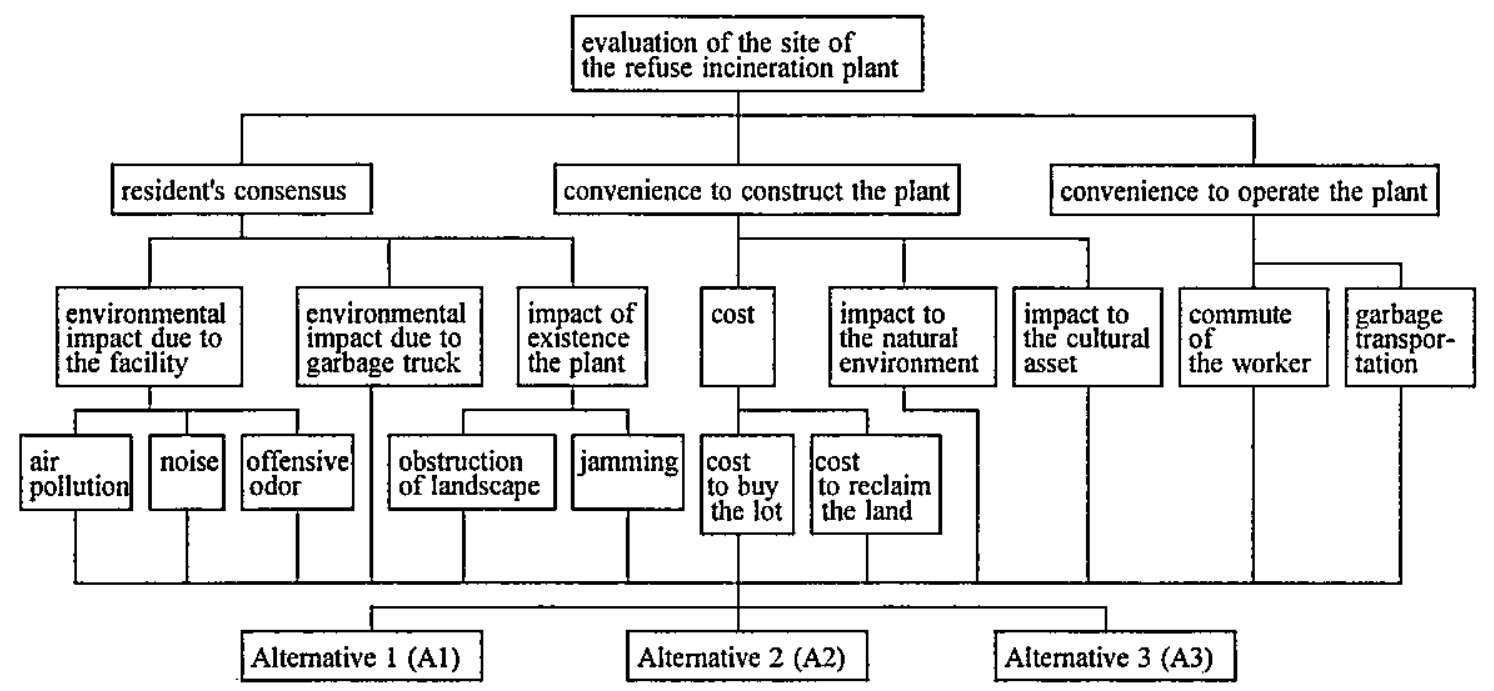

Fig: 3 The hierarchy structure to evaluate the location of refuse incineration plant

\section{Results of the Evaluation}

Asking to the municipal officers attending to the waste disposal, based on the hierarchy structure shown in Fig. 3, we performed pairwise comparison using the algorithm explained in section 3. In table 4, we show the results of the evaluation of the alternatives using Saaty's AHP and D-AHP. Both cases, the alternative 1 (A1) was the most desirable site, A3. was the second, and A2 was the third. Then, we suppose that the alternative 1 is excluded from the both cases, the result of the evaluation is changed as shown in table 5 .

Table 4 The result of the evaluation using AHP

Table 5 The result of AHP excluding the A1

\begin{tabular}{|c|cc|cc|}
\hline \multirow{2}{*}{ Alternatives } & \multicolumn{2}{|c|}{ Saaty's AHP } & \multicolumn{2}{c|}{ D-AHP } \\
\cline { 2 - 5 } & Weight & Rank & Weight & Rank \\
\hline A1 & 0.395 & 1 & 1.802 & 1 \\
\hline A2 & 0.271 & 3 & 1.254 & 3 \\
\hline A3 & 0.333 & 2 & 1.584 & 2 \\
\hline Aspiration level & & & 1.000 & \\
\hline
\end{tabular}

\begin{tabular}{|c|cc|cc|}
\hline \multirow{2}{*}{ Alternatives } & \multicolumn{2}{|c|}{ Saaty's AHP } & \multicolumn{2}{|c|}{ D-AHP } \\
\cline { 2 - 5 } & Weight & Rank & Weight & Rank \\
\hline A2 & 0.539 & 1 & 1.283 & 2 \\
\hline A3 & 0.461 & 2 & 1.877 & 1 \\
\hline Aspiration level & & & 1.000 & \\
\hline
\end{tabular}

The rank reversal occurred in the case of Saaty's AHP, on the other hand the rank is not changed in the case of D-AHP. Further, D-AHP can explain the rank reversal legitimately even the rank reversal may occur.

\section{Conclusion}

A decision support methodology is proposed to evaluate the location of refuse incineration plant to 
dispose the municipal waste for the constructing a new plant using AHP. AHP is a simple method and is valid to analyze the case where include many items to evaluate the alternatives and their relation is complicated. Furthermore, D-AHP is very useful for the case when an alternative is removed from an existing set of alternatives, such as the municipal decision making for siting the refuse incineration plant.

Recently, in japan, according to the policy of the Ministry of Health and Welfare, the refuse incineration plant tends to be constructed a large scale one by plural municipal governments. In this case, the decision making methodologies among multiple decision makers are required. We will propose a multiagency decision support model using D-AHP hereafter.

\section{References}

Barzillai, J., Cook, W.D. and Golany, B. (1987) "Consistent weights for judgements matrices of relative importance of alternatives", Operations research Letters, 6, 131-134.

Belton, V. and Gear, T. (1983) "On a shortcoming of Saaty's method of analytic hierarchies", OMEGA The International Journal of Management Sciences, 11, 228-230.

Dyer, J. S. (1990) "Remarks on the analytic hierarchy process", Management Sciences, 36, 249-258.

Gifford, F. A. (1961) "Use of Routine Meteorological Observations for Estimating Atmospheric Dispersion", Nuclear Safety, 2, 4.

Ministry of Health and Welfare (1998) White Paper on the Health and Welfare in 1997, 411-412 (in Japanese) .

Saaty, T. L. (1980) The Analytic Hierarchy Process, McGraw-Hill, New York.

Tamura, H., Takahashi, S., Hatono, I. and Umano, M. (1997) "On a Descriptive Analytic Hierarchy Process (D-AHP) for Modeling the Legitimacy Rank Reversal", Proceedings of International Conference on Methods and Applications of Multicriteria Decision Making, Mons Belguim 1997, 82-85.

Turner, B. D. (1964) "A Diffusion Model for an Urban Area", Journal of Applied Meteorology, 3, 1-6. 